\title{
TERRESTRIAL LASER SCANNERS SELF-CALIBRATION STUDY: DATUM CONSTRAINTS ANALYSES FOR NETWORK CONFIGURATIONS
}

\author{
Mohd Azwan Abbas ${ }^{\mathrm{a}}$, Halim Setan ${ }^{\mathrm{b}}$, Zulkepli Majid ${ }^{\mathrm{b}}$, Albert K. Chong ${ }^{\mathrm{c}}$, Lau Chong Luh ${ }^{\mathrm{b}}$, Khairulnizam M. Idris ${ }^{\mathrm{b}}$, Mohd Farid \\ Mohd Ariff ${ }^{b}$
}

\author{
a Department of Surveying Science \& Geomatics, Universiti Teknologi MARA, Arau, Perlis, Malaysia \\ ${ }^{b}$ Department of Geomatic Engineering, Universiti Teknologi Malaysia, Skudai, Johor, Malaysia \\ ${ }^{\mathrm{c}}$ Department of Geomatic Engineering, University of Southern Queensland, Australia
}

KEY WORDS: Terrestrial laser scanner, self-calibration, network configuration, datum constraints

\begin{abstract}
:
Similar to other electronic instruments, terrestrial laser scanner (TLS) can also inherent with various systematic errors coming from different sources. Self-calibration technique is a method available to investigate these errors for TLS which were adopted from photogrammetry technique. According to the photogrammetry principle, the selection of datum constraints can cause different types of parameter correlations. However, the network configuration applied by TLS and photogrammetry calibrations are quite different, thus, this study has investigated the significant of photogrammetry datum constraints principle in TLS self-calibration. To ensure that the assessment is thorough, the datum constraints analyses were carried out using three variant network configurations: 1) minimum number of scan stations; 2) minimum number of surfaces for targets distribution; and 3) minimum number of point targets. Based on graphical and statistical, the analyses of datum constraints selection indicated that the parameter correlations obtained are significantly similar. In addition, the analysis has demonstrated that network configuration is a very crucial factor to reduce the correlation between the calculated parameters.
\end{abstract}

\section{INTRODUCTION}

With the speed and accuracy, TLS has been widely used for numerous applications including accurate measurements. They are used for a variety of applications that demand subcentimetre geometric accuracy such as landslide monitoring (Syahmi et al., 2011; Wan Aziz et al., 2012), structural deformation measurement (Gordon and Lichti, 2007; Rönnholm et al., 2009), dam monitoring (González-Aguilera et al., 2008), automobile dimensioning (González-Jorge et al., 2012) and highway clearance measurement (Riveiro et al., 2013), among others.

TLS instruments are complex tools with many moving parts whose relative positions can change over time depending on use, handling frequency and care. Quality assurance (QA) is therefore a critical process to maximize the accuracy by investigate and model the systematic errors consisted in TLS measurement. The investigation procedure can be performed by the well-established self-calibration method (Figure 1). Selfcalibration presents a number of distinct advantages for this purpose (Mohd Azwan et al., 2014):

i. No special calibration facilities are required apart from some form of targeting (usually signalized point targets);

ii. It is based on a rigorous sensor model that includes the basic geometry of data acquisition as well as error models for systematic defects in the individual components and the instrument assembly (e.g. eccentricity and index errors);

iii. It allows incorporation of stochastic models for the observations; and iv. It yields optimal estimates for the model variables along with their precision and reliability (i.e. accuracy) measures.

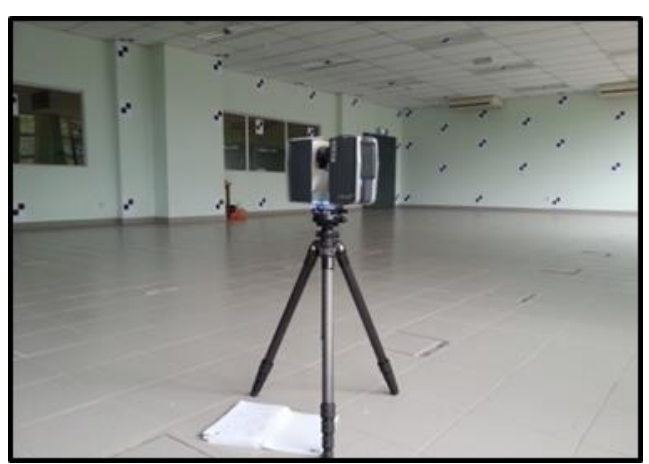

Figure 1. Self-calibration for the Faro Focus 3D scanner.

Since TLS self-calibration was developed from the photogrammetry approach, thus the datum constraints applied for TLS self-calibration are also similar to photogrammetry selfcalibration. There are two types of constraints applicable: (1) ordinary minimum constraints; and (2) inner constraints. However, in photogrammetry self-calibration, the selection of datum constraints can cause different types of parameters correlation (Reshetyuk, 2009). The use of minimum constraints tends to cause large correlation between object points and some of the calibration parameters. For the inner constraints, it has unfavourable property of increasing the correlations between the calibration and exterior orientation parameters.

There are two causes of parameters correlation in selfcalibration: (1) weak network geometry; and (2) the type of constraint used. Lichti (2007) has found that the weak network 
geometry (e.g. limitation size of calibration field and distribution of range) can caused high correlations between calibration parameters and exterior orientation parameters as well as object points. According to the photogrammetry principle, the later (2) causes can lead to different types of parameters correlation. However, network configurations (e.g. targets distribution, size of calibration field and positions of the sensor) required for the self-calibration of TLS (Figure 1) and photogrammetry (Figure 2) are different. Thus, it is quite interesting to investigate whether the photogrammetry principle for the later (2) causes of parameters correlation is applicable for TLS self-calibration.

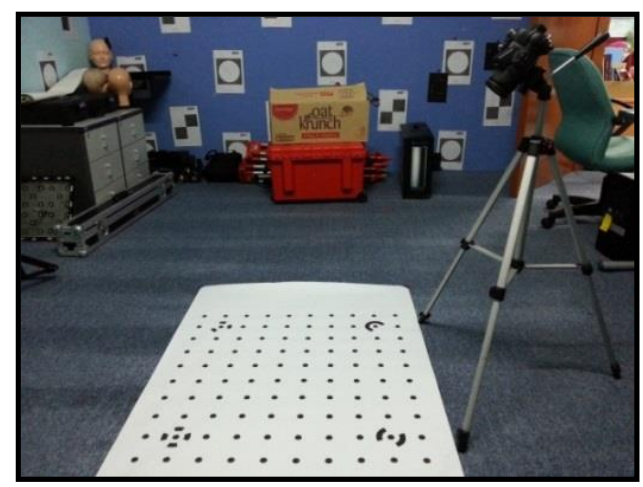

Figure 2. Photogrammetric camera self-calibration using Photomodeler V5.0 software.

The network configuration for TLS self-calibration was addressed in Lichti (2007) as follows:

i. A large variety of ranges is needed to accurately estimate the ranging error terms, in particular the rangefinder offset;

ii. A large range of elevation angle measurements is necessary to recover some of the angular measurement error model coefficients;

iii. The self-calibration can be conducted using a minimum of two separate instrument locations provided that they have orthogonal orientation in the horizontal plane ( $\kappa$ angles, rotation about $\mathrm{Z}$ axis); and

iv. The calibration quality, as measured by reduced parameter correlations, is proportional to the number of targets used.

This argument regarding network configuration has initially indicated that the principle of datum constraints for photogrammetry is not relevant for TLS self-calibration. However, further investigation is a necessity to statistically verify the effect of datum constraints to the quality of TLS selfcalibration. With the intention to scrutinise this issue, the study encompasses three objectives as follow:

i. To evaluate the datum constraints effect of different network configurations;

ii. To determine the suitability of photogrammetry principle of network design for TLS self-calibration; and

iii. To analyse the causes that contribute to high parameter correlations in TLS self-calibration.

In order to achieve the objectives, this study performed selfcalibration for two scanners, Faro Photon 120 and Faro Focus 3D. Both datum constraints were used the bundle adjustment and results were statistically analysed to determine whether there was any significant difference in correlation between the calculated parameters. Furthermore, to ensure this study has critically evaluated this issue, different network configurations were adopted during experiments. Three elements were taken into account for network configurations as follows: (1) the minimum number of scan stations; (2) the minimum number of surfaces on which targets are distributed; and (3) the minimum number of point targets. As a result, analyses of datum constraints were carried out based on full networks and minimum networks configuration according to the described three elements.

\section{GEOMETRIC MODEL FOR SELF-CALIBRATION}

Due to the data measured by TLS are range, horizontal direction and vertical angle, the equations for each measurement are augmented with systematic error correction model as follows (Reshetyuk, 2009):

Range, $r=\sqrt{x^{2}+y^{2}+z^{2}}+\Delta r$

Horizontal direction, $\varphi=\tan ^{-1}\left(\frac{x}{y}\right)+\Delta \varphi$

Vertical angle, $\theta=\tan ^{-1}\left(\frac{z}{\sqrt{x^{2}+y^{2}}}\right)+\Delta \theta$

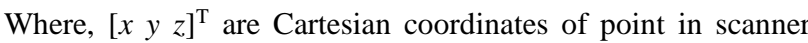
space and $[\Delta r \Delta \varphi \Delta \theta]^{\mathrm{T}}$ are systematic error model for range, horizontal angle and vertical angle, respectively.

Since this study was conducted on panoramic scanners (Faro Photon 120 and Focus 3D), the angular observations computed using equation (2) and equation (3) must be modified. This is due to the scanning procedure applied by panoramic scanner, which rotates only through $180^{\circ}$ to provide $360^{\circ}$ information for horizontal and vertical angles. Compared to hybrid scanner, the mechanism used is similar to total station, rotates $360^{\circ}$ to cover horizontal and vertical views.

Based on Lichti (2010a), the modified mathematical model for a panoramic scanner can be presented as follows:

$$
\begin{aligned}
& \varphi=\tan ^{-1}\left(\frac{x}{y}\right)-180^{\circ} \\
& \theta=180^{\circ}-\tan ^{-1}\left(\frac{z}{\sqrt{x^{2}+y^{2}}}\right)
\end{aligned}
$$

The modified models above, equation (4) and equation (5) are only applicable when horizontal angle is more than $180^{\circ}$. Otherwise, equation (2) and equation (3) will be used, which means that panoramic scanner has two equations for both angular observations. 


\section{EXPERIMENTS}

According to Lichti (2007), the numbers and distribution of targets can affect the results of TLS self-calibration. Thus, with the aim to investigate the concrete evidence of the effect of datum constraints in TLS self-calibration, this study has employed several variations of network configurations as follows:

i. Full network configurations using all targets (138 and 134 for Faro Photon 120 and Faro Focus 3D, respectively), all surfaces (e.g. four walls and a ceiling) and 7 scan stations;

ii. Minimum number of scan stations (e.g. two stations);

iii. Minimum number of surfaces (e.g. two surfaces); and

iv. Minimum number of targets with seventy percent reduction.

Through statistical analysis, the parameter correlations extracted from each network configuration were evaluated. The results obtained concluded whether the photogrammetry principle regarding datum constraints is applicable for TLS selfcalibration.

\subsection{Methodology}

In this study, a self-calibration was performed using two panoramic scanners, Faro Photon 120 and Faro Focus 3D. The calibration was carried out at two different laboratories with roughly similar dimensions, except the length of the room, $15.5 \mathrm{~m}$ (length) $\mathrm{x} 9 \mathrm{~m}$ (width) x $3 \mathrm{~m}$ (height) for Faro Photon 120 and $15 \mathrm{~m}$ length for Faro Focus 3D. The full network configurations were adopted based on Lichti (2007) conditions to ensure the quality of the obtained results is optimal.

Due to the used of different calibration laboratories, there was slightly different in number of targets used, 138 for Faro Photon 120 and 134 for Faro Focus 3D. All targets were welldistributed on the four walls and ceiling. Since the aims of the study is to evaluate the affect of datum constraints selection, which focuses on parameter correlations obtained, thus, small differences in laboratories size and targets distribution can be neglected.

Both scanners employed seven scan stations to observe the targets. As shown in Figure 3, five scan stations were located at the each corner and centre of the room. The other two were positioned close to the two corners with the scanner orientation manually rotated $90^{\circ}$ from scanner orientation at the same corner. In all cases the height of the scanner was placed midway between the floor and the ceiling.

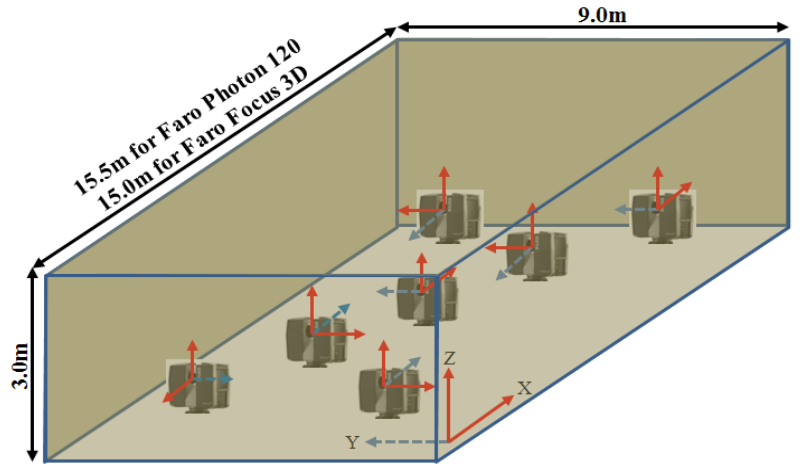

Figure 3. Scanner locations during self-calibration.
With the aid of the Faroscene V5.0 software, all measured targets were extracted except for those that have high incidence angle which were not detectable. A self-calibration bundle adjustment was performed using both datum constraints (e.g. inner and minimum constraints) with precision settings based on the manufacturer's specification, which were $2 \mathrm{~mm}$ for distance and $0.009^{\circ}$ for both angle measurements. After two iterations, the bundle adjustment process converged.

To perform datum constraints analyses, values of correlation coefficient were extracted from variance covariance matrix using the following formula (Abdul and Halim, 2001):

$$
\rho_{x y}=\frac{\sigma_{x y}}{\sigma_{x} \sigma_{y}}
$$

Where,

$$
\begin{aligned}
& \sigma_{x y}: \text { Covariance between parameters. } \\
& \sigma_{x}: \text { Standard deviation of the parameter. }
\end{aligned}
$$

\subsection{Test 1: Minimum Number Of Scan Stations}

Configuration of the full network was discussed in the first three paragraph of Section 3.1. For the second configuration, number of scan stations was reduced from seven scan stations one by one until two scan stations left as shown in Figure 4.

For each time the number of scan station reduced, the selfcalibration bundle adjustment is performed and the datum constraints analyses were carried out. Results obtained could indicate any significant effect of datum constraints selection with variation of scan stations.

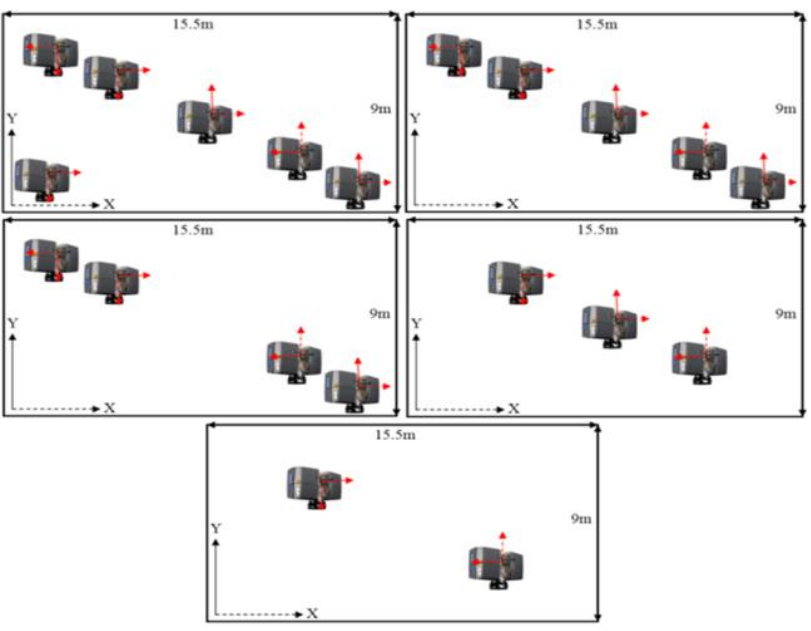

Figure 4. Reducing number of scan stations during selfcalibration.

\subsection{Test 2: Minimum Number Of Surfaces}

The subsequent network configuration focuses on reducing the numbers of surfaces used for target distribution. This is very crucial due to the difficulty to get surfaces similar as laboratory condition for on-site application. In laboratory, all targets can be distributed to the walls, a ceiling and a floor. But for on-site situation, sometimes there are only two walls and a floor available. In this study, four walls and a ceiling were used to distribute all targets. From these five surfaces, experiment was carry out by removing those surfaces one by one until two 
surfaces left as shown in Figure 5. For each removing procedure, self-calibration bundle adjustment was performed and followed with datum constraints analyses.
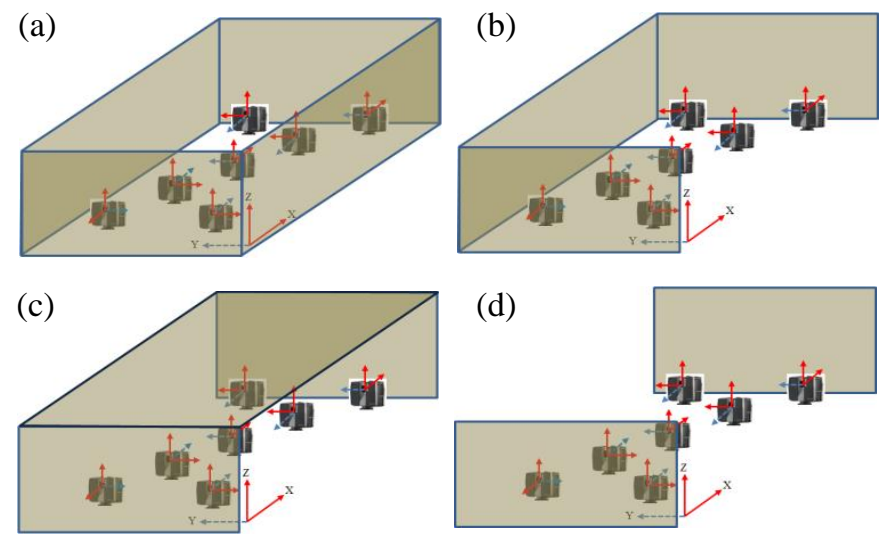

Figure 5. Reducing number of surfaces for targets distribution, (a) Four surfaces by removing a ceiling, (b) Three surfaces by removing a ceiling and a length wall, (c) Three surfaces by removing both length walls and (d) two surfaces.

\subsection{Test 3: Minimum Number Of Targets}

The final network configuration was carried out to investigate minimum number of targets which are suitable for TLS selfcalibration. This experiment was implemented by reducing the number targets from all surfaces for by every ten percent (Figure 6a) until seventy percent (Figure 6b) were removed. As illustrate in Figure 6, all seven scanners were used in this test to observe the targets. To maintain the quality of self-calibration result, in each trial, the targets have been well distributed. As applied in the previous experiments, each time when the targets reduced, self-calibration bundle adjustment is carried and followed with datum constraints analyses.

(a)

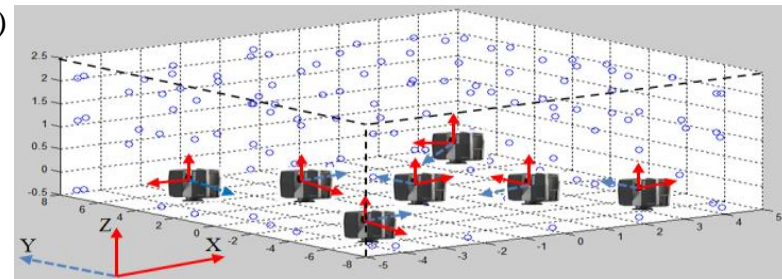

(b)

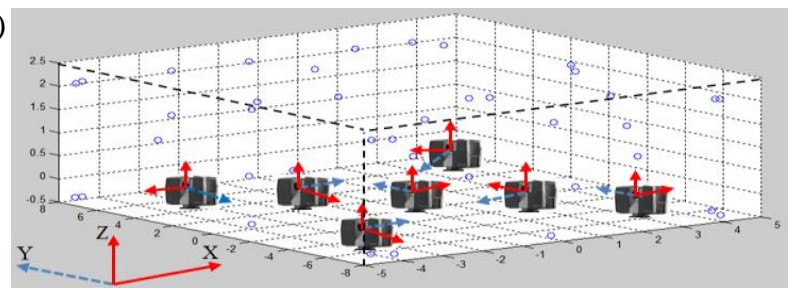

Figure 5. Reducing the number of targets, (a) Ten percent targets reduced and (b) Seventy percent targets reduced.

\section{DATUM CONSTRAINTS}

Terrestrial laser scanner data involves 3D network, thus, theoretically seven datum constraints are required to remove datum defects. However, with the range observation, the scale is defined implicitly, which means that scanner network only requires six datum constraints.
To employ minimum constraints, all six datum need to be fixed. There are several procedures available to implement minimum constraints:

i. According to Reshetyuk (2009), six fix coordinates distributed over 3 non-collinear points are required in order to use minimum constraints; or

ii. As applied by Gielsdorf et al. (2004), position and orientation of one scanner station which represent by exterior orientation parameters were fixed to employ minimum constraints.

In order to use the minimum constraints, this study has fixed the exterior orientation parameters for the first scanner station. For the inner constraints, the method discussed in Mohd Azwan et al. (2014) was adopted.

\subsection{Statistical Analysis}

Correlations analyses were carried out between the calibration parameters and other system parameters (e.g. exterior orientation parameters and object points). To assess the significant difference in datum constraints selection, several graphs were plotted to visualise the difference between the parameter correlations of inner and minimum constraints. Furthermore, statistical analysis was performed to evaluate the results obtained from the plotted graphs. The F-variance ratio test was used to investigate the significance of the difference between two populations (Gopal, 1999). The null hypothesis, $\mathrm{H}_{0}$, of the test is that the two population variances are not significantly different while the alternate hypothesis is that they are different. The F-variance ratio test is defined as:

$\mathrm{F}=\frac{\sigma_{1}^{2}}{\sigma_{2}^{2}}$

Where $\sigma_{1}^{2}$ is variance of population 1 . The null hypothesis is rejected if the calculated $F$ value is higher than the critical $F$ value (from the F-distribution table) at the 5\% significance level. The rejection of $\mathrm{H}_{0}$ shows that the test parameters are not equal. If the test shows no significant difference, then both datum constraints are suitable for the self-calibration bundle adjustment for terrestrial laser scanner.

\section{RESULTS AND ANALYSES}

As discussed in Section 1, one of the causes of parameters correlation is the type of constraints used. Furthermore, Reshetyuk (2009) mentioned that selection of datum constraints can results different types of parameters correlation in photogrammetry application. Thus, investigation is carried to ensure whether that principal is applicable for TLS selfcalibration. Through graphical and statistical analysis, the results obtained are discussed in detail.

Below are the plotted graphs (Figure 6 to Figure 10) illustrated the comparison of parameters correlation between inner and minimum constraints for both scanners, which employed full network configuration. Due to the large number of parameters involved (e.g. seven scan stations, four calibration parameters and more than hundred targets) in variance covariance matrix, then this study has used the mean values. 


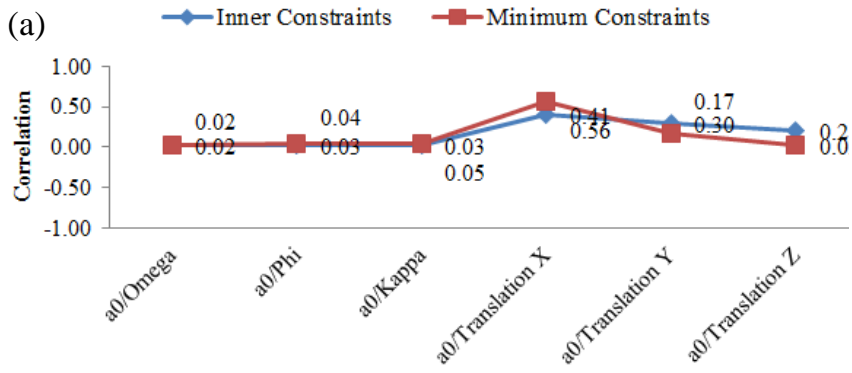

(b) Correlation of Constant Range and Exterior Orientation Parameters

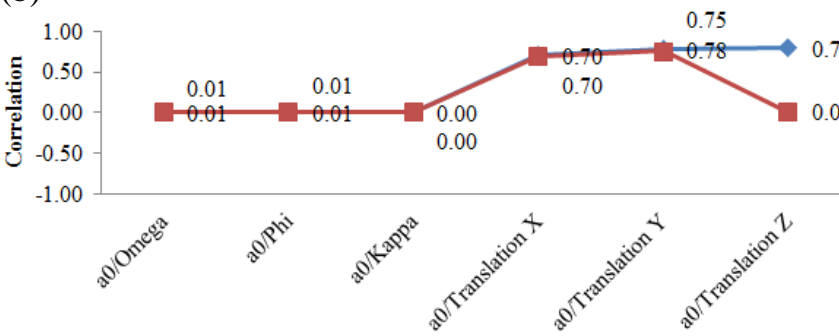

Correlation of Constant Range and Exterior Orientation Parameters

Figure 6. Parameter correlations of constant range and exterior orientation parameters (full network configuration), (a) Faro Photon 120 and (b) Faro Focus 3D.

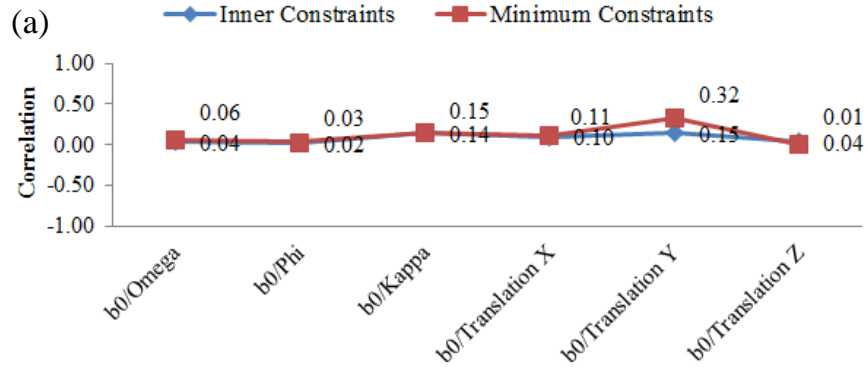

(b) Correlation of Collimation Axis and Exterior Orientation Parameters

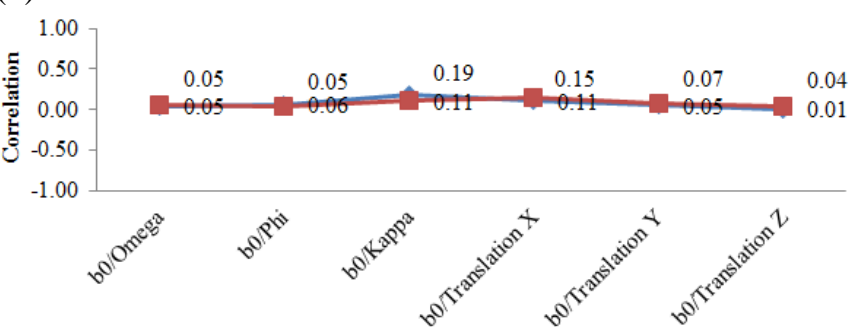

Correlation of Collimation Axis and Exterior Orientation Parameters

Figure 7. Parameter correlations of collimation axis and exterior orientation parameters (full network configuration) ), (a) Faro Photon 120 and (b) Faro Focus 3D.

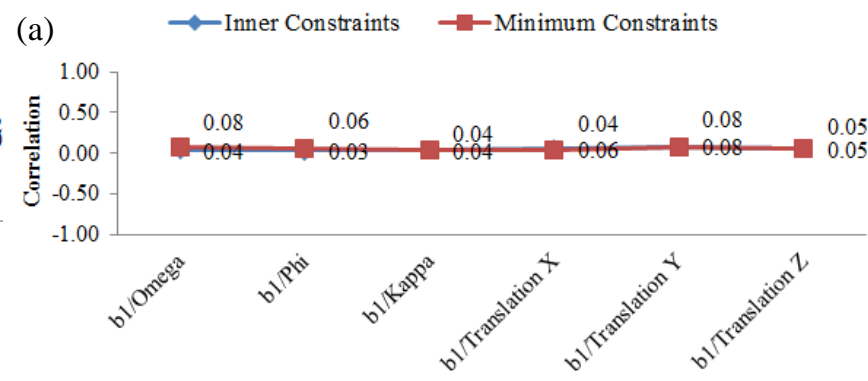

(b) Correlation of Trunnion Axis and Exterior Orientation Parameters

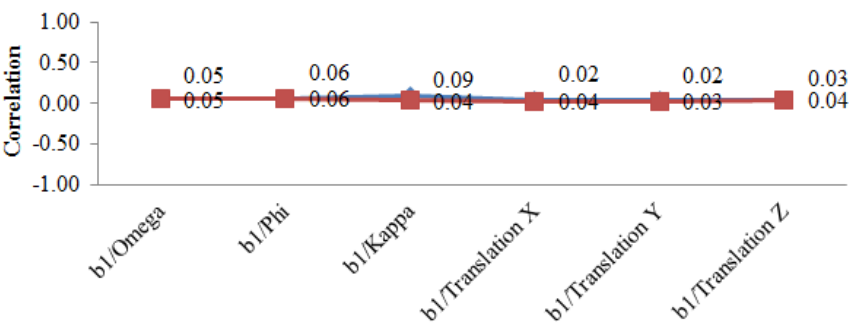

Correlation of Trunnion Axis and Exterior Orientation Parameters

Figure 8. Parameter correlations of trunnion axis and exterior orientation parameters (full network configuration) ), (a) Faro Photon 120 and (b) Faro Focus 3D.

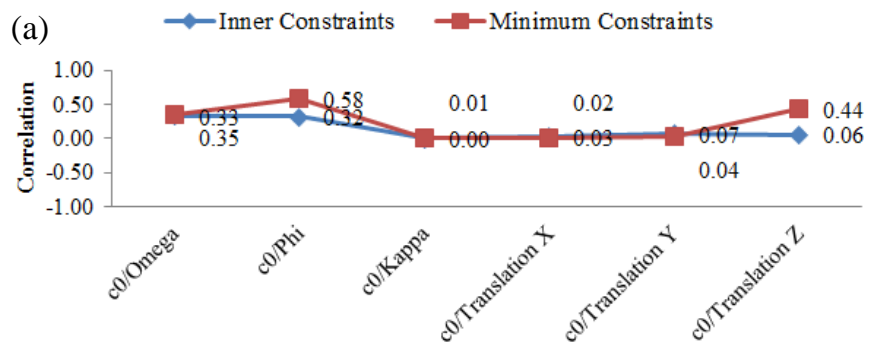

(b)

Correlation of Vertical Circle Index and Exterior Orientation

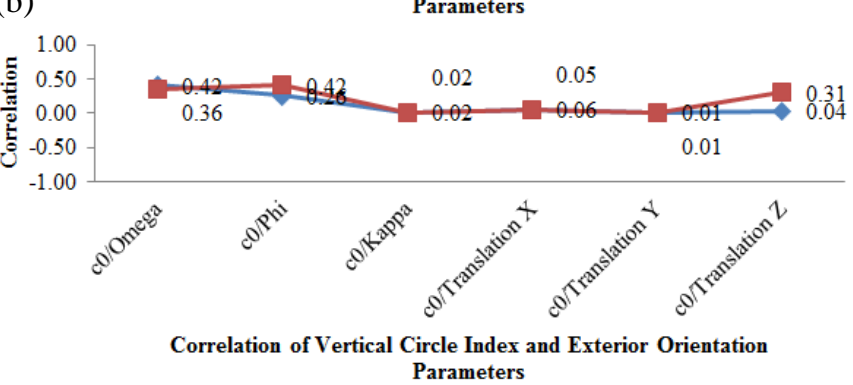

Figure 9. Parameter correlations of vertical circle index and exterior orientation parameters (full network configuration), (a) Faro Photon 120 and (b) Faro Focus 3D.

Lichti (2010b) in his study discussed the sources of correlation in TLS self-calibration of a basic calibration parameters (e.g. a0, $\mathrm{b}_{0}, \mathrm{~b}_{1}$ and $\left.\mathrm{c}_{0}\right)$. The constant range $\left(\mathrm{a}_{0}\right)$ has high correlation with the scanner position (e.g. translation for $\mathrm{X}, \mathrm{Y}$ and $\mathrm{Z}$ ), while

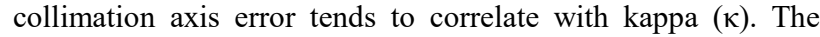
correlations in trunnion axis error only emerge when an asymmetric target distribution exists and the vertical circle index error is highly correlated with omega $(\omega)$ and phi $(\phi)$.

Figure 6 to Figure 8 represents the plotted correlation between four calibration parameters and exterior orientation (EO) parameters (e.g. omega, phi, kappa, translation X, translation Y and translation $\mathrm{Z}$ ). According to the correlation tendency 
described in Lichti (2010b), similar trends have been illustrated in Figure 6 until Figure 8. As the aim of this study is to investigate the datum constraints effect in TLS self-calibration, each graph provides the comparison of parameter correlation yielded from using inner (blue line) and minimum (red line) constraints.

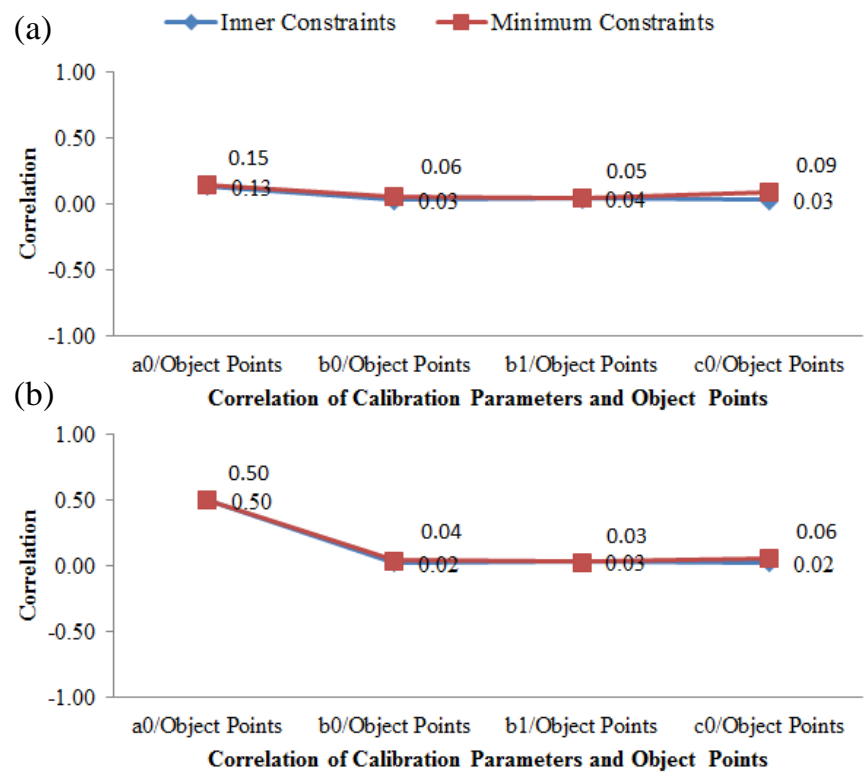

Figure 10. Parameter correlations of calibration parameters and object points (full network configuration), (a) Faro Photon 120 and (b) Faro Focus 3D.

Figure 10 is depicting the correlation of calibration parameters with object points. Through the visual evaluation, initial conclusion can be made that the parameter correlation produced from both datum constraints are significantly similar. Although there are several outliers presented with maximum differences are 0.38 (between vertical circle index, $\mathrm{c}_{0}$ and translation $\mathrm{Z}$ in Figure 9a) for Faro Photon 120 and 0.77 (between constant range, ao and translation $\mathrm{Z}$ in Figure 6b) for Faro Focus 3D. However, these large discrepancies can be considered as uncertainty due to the minor differences shown by the other scanner, which are 027 in Figure $9 \mathrm{~b}$ (for Faro Focus 3D) and 0.18 in Figure 6a (for Faro Photon 120). Through statistical analysis, F-variance ratio test has mathematically proved the similarity of results obtained.

Table 1. F-variance ratio test for full network configuration.

\begin{tabular}{lcccc}
\hline $\begin{array}{l}\text { Parameter } \\
\text { Correlations }\end{array}$ & $\begin{array}{c}\text { Calculated F for Faro } \\
\text { Photon 120 }\end{array}$ & Focus 3D & $><$ & Critical F \\
\hline $\mathrm{a}_{0} /$ EO & 0.09 & 0.35 & $<$ & $5 \cdot 05$ \\
$\mathrm{~b}_{0} /$ EO & 0.42 & 0.001 & $<$ & $5 \cdot 05$ \\
$\mathrm{~b}_{1} /$ EO & 0.01 & 2.50 & $<$ & $5 \cdot 05$ \\
$\mathrm{c}_{0} /$ EO & 0.69 & 0.33 & $<$ & 5.05 \\
$\mathrm{CP} /$ OP & 0.01 & 0.01 & $<$ & $9 \cdot 28$ \\
\hline
\end{tabular}

Table 1 shows that in all cases, with $95 \%$ confidence level, the calculated $F$ is smaller than critical $F$, which indicates the acceptation of null hypothesis $\left(\mathrm{H}_{0}\right)$. In other words, comparison of parameters correlation calculated from using inner and minimum constraints have demonstrated a significant similarity. Since this is the results of full network which have employed very strong network geometry, thus, the good findings is expected.
With the intention to investigate the robustness conclusion regarding similarity of the correlation results yielded from both datum constraints, this study has carried out similar analysis for different type of network configurations. The first configuration is by reducing the number of scan stations. For each stations configuration, statistical analysis is performed as depicted in Table 2. For all cases, the calculated $\mathrm{F}$ for both scanners are smaller than critical F. In other words, the null hypothesis are accepted which mean no significant difference between both datum constraints.

Table 2. F-variance ratio test for different stations configurations.

\begin{tabular}{|c|c|c|c|c|c|}
\hline \multirow{2}{*}{ Configuration } & \multirow{2}{*}{$\begin{array}{l}\text { Parameter } \\
\text { Correlations }\end{array}$} & \multicolumn{2}{|c|}{$\begin{array}{c}\text { Calculated } \mathrm{F} \text { for } \\
\text { Faro: }\end{array}$} & \multirow{2}{*}{$>/<$} & \multirow{2}{*}{$\begin{array}{c}\text { Critical } \\
\text { F }\end{array}$} \\
\hline & & $\begin{array}{c}\text { Photon } \\
120\end{array}$ & $\begin{array}{c}\text { Focus } \\
3 \mathrm{D}\end{array}$ & & \\
\hline \multirow{5}{*}{6 Stations } & $\mathrm{a}_{0} / \mathrm{EO}$ & $0 \cdot 07$ & $0 \cdot 22$ & $<$ & $5 \cdot 05$ \\
\hline & $\mathrm{b}_{0} / \mathrm{EO}$ & $0 \cdot 18$ & 0.00 & $<$ & 5.05 \\
\hline & $\mathrm{b}_{1} / \mathrm{EO}$ & $0 \cdot 16$ & $2 \cdot 48$ & $<$ & 5.05 \\
\hline & $\mathrm{c}_{0} / \mathrm{EO}$ & $0 \cdot 71$ & $0 \cdot 27$ & $<$ & $5 \cdot 05$ \\
\hline & $\mathrm{CP} / \mathrm{OP}$ & $0 \cdot 86$ & $0 \cdot 01$ & $<$ & $9 \cdot 28$ \\
\hline \multirow{5}{*}{5 Stations } & $\mathrm{a}_{0} / \mathrm{EO}$ & $0 \cdot 05$ & $0 \cdot 13$ & $<$ & $5 \cdot 05$ \\
\hline & $\mathrm{b}_{0} / \mathrm{EO}$ & $0 \cdot 37$ & 0.01 & $<$ & 5.05 \\
\hline & $\mathrm{b}_{1} / \mathrm{EO}$ & 0.00 & $2 \cdot 80$ & $<$ & $5 \cdot 05$ \\
\hline & $\mathrm{c}_{0} / \mathrm{EO}$ & 0.63 & 0.28 & $<$ & 5.05 \\
\hline & $\mathrm{CP} / \mathrm{OP}$ & $0 \cdot 86$ & 0.02 & $<$ & $9 \cdot 28$ \\
\hline \multirow{5}{*}{4 Stations } & $\mathrm{a}_{0} / \mathrm{EO}$ & $0 \cdot 17$ & $0 \cdot 26$ & $<$ & $5 \cdot 05$ \\
\hline & $\mathrm{b}_{0} / \mathrm{EO}$ & $0 \cdot 32$ & 0.00 & $<$ & 5.05 \\
\hline & $\mathrm{b}_{1} / \mathrm{EO}$ & $0 \cdot 21$ & 2.08 & $<$ & $5 \cdot 05$ \\
\hline & $\mathrm{c}_{0} / \mathrm{EO}$ & $0 \cdot 77$ & $0 \cdot 82$ & $<$ & 5.05 \\
\hline & $\mathrm{CP} / \mathrm{OP}$ & $0 \cdot 75$ & 0.02 & $<$ & $9 \cdot 28$ \\
\hline \multirow{5}{*}{3 Stations } & $\mathrm{a}_{0} / \mathrm{EO}$ & 0.06 & 0.07 & $<$ & 5.05 \\
\hline & $\mathrm{b}_{0} / \mathrm{EO}$ & 0.00 & 0.33 & $<$ & $5 \cdot 05$ \\
\hline & $\mathrm{b}_{1} / \mathrm{EO}$ & 1.63 & 0.73 & $<$ & 5.05 \\
\hline & $\mathrm{c}_{0} / \mathrm{EO}$ & $0 \cdot 47$ & 128 & $<$ & $5 \cdot 05$ \\
\hline & $\mathrm{CP} / \mathrm{OP}$ & $0 \cdot 19$ & 0.02 & $<$ & $9 \cdot 28$ \\
\hline \multirow{5}{*}{2 Stations } & $\mathrm{a}_{0} / \mathrm{EO}$ & $0 \cdot 14$ & $0 \cdot 27$ & $<$ & $5 \cdot 05$ \\
\hline & $\mathrm{b}_{0} / \mathrm{EO}$ & $0 \cdot 11$ & 0.03 & $<$ & $5 \cdot 05$ \\
\hline & $\mathrm{b}_{1} / \mathrm{EO}$ & $0 \cdot 15$ & 0.39 & $<$ & 5.05 \\
\hline & $\mathrm{c}_{0} / \mathrm{EO}$ & $0 \cdot 15$ & $0 \cdot 48$ & $<$ & 5.05 \\
\hline & $\mathrm{CP} / \mathrm{OP}$ & $0 \cdot 11$ & $0 \cdot 11$ & $<$ & $9 \cdot 28$ \\
\hline
\end{tabular}

Through different surfaces configurations experiment, the datum constraints analysis was again performed. Outcomes of F-variance ratio test were organised in the Table 3 for four different types of surfaces configurations. Values of calculated $\mathrm{F}$ for all circumstances have indicated the acceptance of null hypothesis, which also has increase the certainty of previous conclusion, there is no significant effect in datum constraints selection.

For the final configuration, different number of targets distribution, F-variance ratio test has concretely proved that there is no significant effect in parameter correlations from the datum constraints selection. As shown in Table 4, the null hypotheses have again statistically verified the significant similarity of both datum constraints. 
Table 3. F-variance ratio test for different surfaces configurations.

\begin{tabular}{|c|c|c|c|c|c|}
\hline \multirow{2}{*}{ Configuration } & \multirow{2}{*}{$\begin{array}{l}\text { Parameter } \\
\text { Correlations }\end{array}$} & \multicolumn{2}{|c|}{$\begin{array}{c}\text { Calculated } \mathrm{F} \text { for } \\
\text { Faro: }\end{array}$} & \multirow{2}{*}{$>/<$} & \multirow{2}{*}{$\begin{array}{c}\text { Critical } \\
\text { F }\end{array}$} \\
\hline & & $\begin{array}{c}\text { Photon } \\
120\end{array}$ & $\begin{array}{c}\text { Focus } \\
3 \mathrm{D}\end{array}$ & & \\
\hline \multirow{5}{*}{4 Walls } & $\mathrm{a}_{0} / \mathrm{EO}$ & $0 \cdot 01$ & $0 \cdot 32$ & $<$ & $5 \cdot 05$ \\
\hline & $\mathrm{b}_{0} / \mathrm{EO}$ & $0 \cdot 25$ & 0.04 & $<$ & 5.05 \\
\hline & $\mathrm{b}_{1} / \mathrm{EO}$ & $3 \cdot 18$ & 1.53 & $<$ & $5 \cdot 05$ \\
\hline & $\mathrm{c}_{0} / \mathrm{EO}$ & $0 \cdot 61$ & $0 \cdot 25$ & $<$ & $5 \cdot 05$ \\
\hline & $\mathrm{CP} / \mathrm{OP}$ & 0.69 & 0.00 & $<$ & $9 \cdot 28$ \\
\hline \multirow{5}{*}{$\begin{array}{l}2 \text { Walls and a } \\
\text { Ceiling }\end{array}$} & $\mathrm{a}_{0} / \mathrm{EO}$ & 0.01 & $0 \cdot 35$ & $<$ & 5.05 \\
\hline & $\mathrm{b}_{0} / \mathrm{EO}$ & 026 & 0.00 & $<$ & 5.05 \\
\hline & $\mathrm{b}_{1} / \mathrm{EO}$ & 160 & $1 \cdot 16$ & $<$ & 5.05 \\
\hline & $\mathrm{c}_{0} / \mathrm{EO}$ & 0.56 & $0 \cdot 37$ & $<$ & 5.05 \\
\hline & $\mathrm{CP} / \mathrm{OP}$ & $0 \cdot 31$ & 0.01 & $<$ & $9 \cdot 28$ \\
\hline \multirow{5}{*}{3 Walls } & $\mathrm{a}_{0} / \mathrm{EO}$ & 0.00 & $0 \cdot 30$ & $<$ & $5 \cdot 05$ \\
\hline & $\mathrm{b}_{0} / \mathrm{EO}$ & 0.50 & 0.02 & $<$ & 5.05 \\
\hline & $\mathrm{b}_{1} / \mathrm{EO}$ & $0 \cdot 81$ & 0.55 & $<$ & $5 \cdot 05$ \\
\hline & $\mathrm{c}_{0} / \mathrm{EO}$ & 0.63 & $0 \cdot 26$ & $<$ & $5 \cdot 05$ \\
\hline & $\mathrm{CP} / \mathrm{OP}$ & $0 \cdot 40$ & 0.02 & $<$ & $9 \cdot 28$ \\
\hline \multirow{5}{*}{2 Walls } & $\mathrm{a}_{0} / \mathrm{EO}$ & 0.00 & 028 & $<$ & $5 \cdot 05$ \\
\hline & $\mathrm{b}_{0} / \mathrm{EO}$ & 0.07 & $0 \cdot 44$ & $<$ & $5 \cdot 05$ \\
\hline & $\mathrm{b}_{1} / \mathrm{EO}$ & $0 \cdot 40$ & 0.33 & $<$ & 5.05 \\
\hline & $\mathrm{c}_{0} / \mathrm{EO}$ & $0 \cdot 40$ & $0 \cdot 29$ & $<$ & 5.05 \\
\hline & $\mathrm{CP} / \mathrm{OP}$ & 0.02 & 0.01 & $<$ & $9 \cdot 28$ \\
\hline
\end{tabular}

As discussed in Section 1, according to photogrammetry selfcalibration, the used of inner constraints can increase the correlations between the calibration parameters and exterior orientations. In addition, employing minimum constraints tends to cause large correlations between object points and calibration parameters. However, trend in the graphs plotted (e.g. for full network, minimum stations, minimum surfaces and minimum targets configurations) indicates different assumption. Surprisingly, for all plotted graphs, the comparisons between the parameter correlations obtained from using both datum constraints are quite similar. Since the only causes for parameter correlation are network geometry and selection of datum constraints, thus, the outcomes of this study has graphically and statistically proved that the later cause is not relevant for TLS self-calibration. However, the network geometry should be made carefully, this is very crucial to ensure the quality of the results obtained (e.g. calibration parameters as well as to decorrelate the parameters).

According to Figure 10, the plotted average parameter correlation (of inner and minimum constraints) with respect to the different network configurations have indicated the important things that should be considered to reduce the correlation between calculated parameters. As illustrated in Figure 10a and Figure 10b which represent the parameter correlation for Faro Photon 120 and Faro Focus 3D, respectively, the full network configuration has minimum correlation for both scanners. However, there are several results showing that minimum surfaces and targets configuration have comparable parameter correlations to full network configuration (for both scanners). This may be due to the influence of bad incidence angle caused by the used of all targets in full network configuration. In contrast, minimum surfaces and targets configurations have used reduced targets which are perpendicular to the scanner position. Nevertheless, the plotted graph in Figure 10a and Figure 10b for both scanners have mathematically and visually proved that network configuration has an important role compared to datum constraints, in order to reduce the parameter correlation.

(a) $\multimap$ Full Network $\rightarrow$ Minimum Stations $\leftarrow$ Minimum Surfaces $\leftarrow$ Minimum Targets

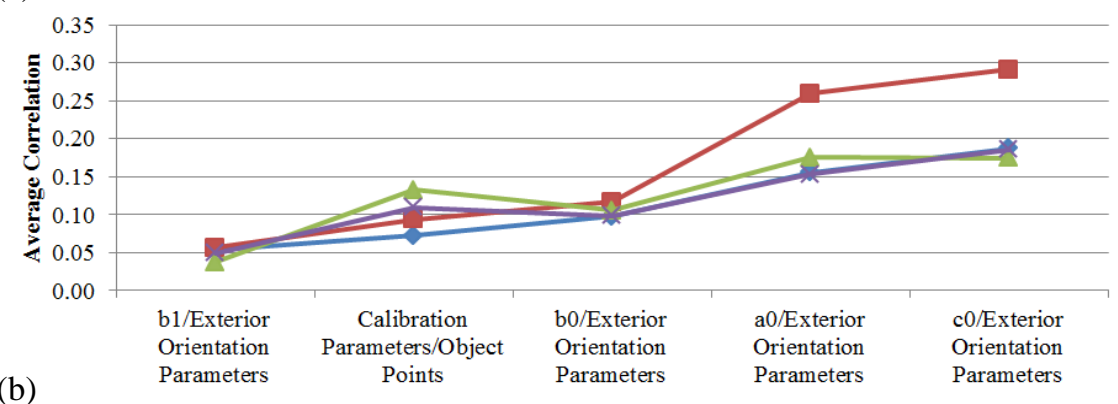

(b)

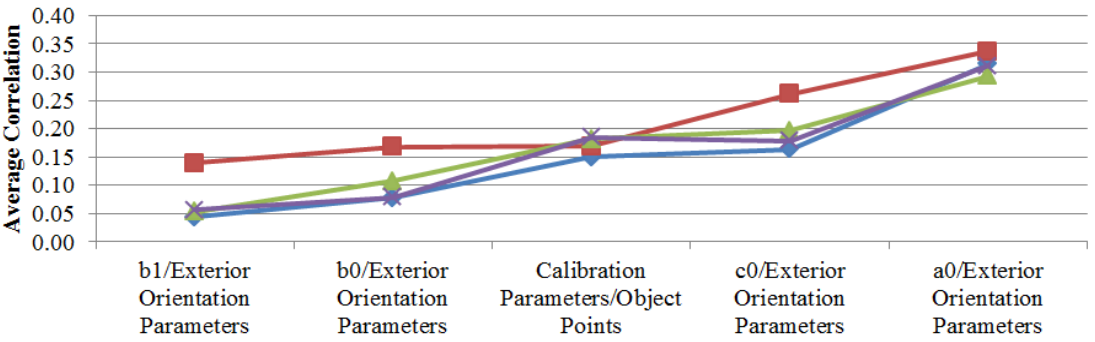

Figure 11. Average parameter correlation (of inner and minimum constraints) with respect to the network configurations), (a) Faro Photon 120 and (b) Faro Focus 3D. 
Table 4. F-variance ratio test for different targets configurations.

\begin{tabular}{|c|c|c|c|c|c|}
\hline \multirow{2}{*}{ Configuration } & \multirow{2}{*}{$\begin{array}{l}\text { Parameter } \\
\text { Correlations }\end{array}$} & \multicolumn{2}{|c|}{ Calculated $\mathrm{F}$ for } & \multirow{2}{*}{$>/<$} & \multirow{2}{*}{$\begin{array}{c}\text { Critical } \\
\text { F }\end{array}$} \\
\hline & & $\begin{array}{c}\text { Photon } \\
120\end{array}$ & $\begin{array}{c}\text { Focus } \\
3 \mathrm{D}\end{array}$ & & \\
\hline \multirow{5}{*}{$\begin{array}{l}10 \% \text { Targets } \\
\text { Reduction }\end{array}$} & $\mathrm{a}_{0} / \mathrm{EO}$ & 0.07 & $0 \cdot 35$ & $<$ & $5 \cdot 05$ \\
\hline & $\mathrm{b}_{0} / \mathrm{EO}$ & $0 \cdot 20$ & $0 \cdot 00$ & $<$ & $5 \cdot 05$ \\
\hline & $\mathrm{b}_{1} / \mathrm{EO}$ & 0.53 & 3.07 & $<$ & $5 \cdot 05$ \\
\hline & $\mathrm{c}_{0} / \mathrm{EO}$ & 0.61 & $0 \cdot 30$ & $<$ & $5 \cdot 05$ \\
\hline & $\mathrm{CP} / \mathrm{OP}$ & 0.52 & $0 \cdot 01$ & $<$ & $9 \cdot 28$ \\
\hline \multirow{5}{*}{$\begin{array}{l}20 \% \text { Targets } \\
\text { Reduction }\end{array}$} & $\mathrm{a}_{0} / \mathrm{EO}$ & 0.08 & $0 \cdot 36$ & $<$ & $5 \cdot 05$ \\
\hline & $\mathrm{b}_{0} / \mathrm{EO}$ & $0 \cdot 27$ & 0.00 & $<$ & $5 \cdot 05$ \\
\hline & $\mathrm{b}_{1} / \mathrm{EO}$ & $0 \cdot 27$ & 2.98 & $<$ & $5 \cdot 05$ \\
\hline & $\mathrm{c}_{0} / \mathrm{EO}$ & $0 \cdot 61$ & $0 \cdot 33$ & $<$ & $5 \cdot 05$ \\
\hline & $\mathrm{CP} / \mathrm{OP}$ & $0 \cdot 45$ & $0 \cdot 01$ & $<$ & $9 \cdot 28$ \\
\hline \multirow{5}{*}{$\begin{array}{l}30 \% \text { Targets } \\
\text { Reduction }\end{array}$} & $\mathrm{a}_{0} / \mathrm{EO}$ & $0 \cdot 10$ & $0 \cdot 36$ & $<$ & $5 \cdot 05$ \\
\hline & $\mathrm{b}_{0} / \mathrm{EO}$ & $0 \cdot 39$ & $0 \cdot 04$ & $<$ & $5 \cdot 05$ \\
\hline & $\mathrm{b}_{1} / \mathrm{EO}$ & $0 \cdot 29$ & $2 \cdot 10$ & $<$ & $5 \cdot 05$ \\
\hline & $\mathrm{c}_{0} / \mathrm{EO}$ & $0 \cdot 62$ & $0 \cdot 35$ & $<$ & $5 \cdot 05$ \\
\hline & $\mathrm{CP} / \mathrm{OP}$ & 0.61 & 0.02 & $<$ & $9 \cdot 28$ \\
\hline \multirow{5}{*}{$\begin{array}{l}40 \% \text { Targets } \\
\text { Reduction }\end{array}$} & $\mathrm{a}_{0} / \mathrm{EO}$ & 0.09 & $0 \cdot 35$ & $<$ & $5 \cdot 05$ \\
\hline & $\mathrm{b}_{0} / \mathrm{EO}$ & $0 \cdot 28$ & $0 \cdot 05$ & $<$ & $5 \cdot 05$ \\
\hline & $\mathrm{b}_{1} / \mathrm{EO}$ & 0.52 & 1.73 & $<$ & $5 \cdot 05$ \\
\hline & $\mathrm{c}_{0} / \mathrm{EO}$ & 0.56 & $0 \cdot 29$ & $<$ & $5 \cdot 05$ \\
\hline & $\mathrm{CP} / \mathrm{OP}$ & 0.58 & 0.01 & $<$ & $9 \cdot 28$ \\
\hline \multirow{5}{*}{$\begin{array}{l}50 \% \text { Targets } \\
\text { Reduction }\end{array}$} & $\mathrm{a}_{0} / \mathrm{EO}$ & 0.09 & $0 \cdot 36$ & $<$ & $5 \cdot 05$ \\
\hline & $\mathrm{b}_{0} / \mathrm{EO}$ & $0 \cdot 27$ & $0 \cdot 10$ & $<$ & $5 \cdot 05$ \\
\hline & $\mathrm{b}_{1} / \mathrm{EO}$ & 1.22 & 121 & $<$ & $5 \cdot 05$ \\
\hline & $\mathrm{c}_{0} / \mathrm{EO}$ & 0.55 & $0 \cdot 29$ & $<$ & $5 \cdot 05$ \\
\hline & $\mathrm{CP} / \mathrm{OP}$ & $0 \cdot 30$ & 0.02 & $<$ & $9 \cdot 28$ \\
\hline \multirow{5}{*}{$\begin{array}{l}60 \% \text { Targets } \\
\text { Reduction }\end{array}$} & $\mathrm{a}_{0} / \mathrm{EO}$ & 0.08 & $0 \cdot 35$ & $<$ & $5 \cdot 05$ \\
\hline & $\mathrm{b}_{0} / \mathrm{EO}$ & $0 \cdot 18$ & $0 \cdot 01$ & $<$ & $5 \cdot 05$ \\
\hline & $\mathrm{b}_{1} / \mathrm{EO}$ & $0 \cdot 61$ & $0 \cdot 17$ & $<$ & $5 \cdot 05$ \\
\hline & $\mathrm{c}_{0} / \mathrm{EO}$ & 0.56 & $0 \cdot 23$ & $<$ & $5 \cdot 05$ \\
\hline & $\mathrm{CP} / \mathrm{OP}$ & $0 \cdot 27$ & 0.02 & $<$ & $9 \cdot 28$ \\
\hline \multirow{5}{*}{$\begin{array}{l}70 \% \text { Targets } \\
\text { Reduction }\end{array}$} & $\mathrm{a}_{0} / \mathrm{EO}$ & $0 \cdot 10$ & $0 \cdot 34$ & $<$ & $5 \cdot 05$ \\
\hline & $\mathrm{b}_{0} / \mathrm{EO}$ & $0 \cdot 14$ & $0 \cdot 00$ & $<$ & $5 \cdot 05$ \\
\hline & $\mathrm{b}_{1} / \mathrm{EO}$ & $0 \cdot 01$ & $0 \cdot 20$ & $<$ & $5 \cdot 05$ \\
\hline & $\mathrm{c}_{0} / \mathrm{EO}$ & $0 \cdot 71$ & $0 \cdot 20$ & $<$ & $5 \cdot 05$ \\
\hline & $\mathrm{CP} / \mathrm{OP}$ & $0 \cdot 30$ & $0 \cdot 01$ & $<$ & $9 \cdot 28$ \\
\hline
\end{tabular}

\section{CONCLUSIONS}

A self-calibration procedure used for TLS calibration was originally adapted from photogrammetry technique, however the photogrammetry network configuration is not suitable for TLS application. This is due to the observables and measurement technique implemented by both photogrammetry and TLS are different. Therefore, further investigation was carried out to evaluate whether similar effect in datum constraints selection for photogrammetry is relevant for TLS. Graphical and statistical analyses were employed to examine any significant differences in the parameter correlations obtained from inner or minimum constraints.

To ensure that the investigation is thoroughly executed, the datum constraints analyses were carried out using three variant network configurations: 1) minimum number of scan stations, 2) minimum number of surfaces for targets distribution, and 3) minimum number of point targets. The datum constraints analyses for all network configurations have indicated that the selection of datum constraints does not affect the values of parameter correlations. Both inner and minimum constraints can provide significantly similar parameter correlations.
Nevertheless, the network configuration is a very crucial procedure to ensure that the correlation between the calculated parameters can be reduced.

Since both scanners employed in this study are using panoramic system, it is quite interesting to implement similar analysis for the hybrid system scanner. Furthermore, the measurement mechanism used in panoramic and hybrid scanners are different, thus, further research will focus on the investigation of datum constraints effect for the hybrid scanner.

\section{ACKNOWLEDGEMENTS}

The present research was made possible through a guide from Professor Doctor Derek D. Lichti from University of Calgary in helping to build the bundle adjustment program. Special thanks goes to Ministry of Higher Education (MoHE) and Photogrammetry \& Laser Scanning Research Group, INFOCOMM Research Alliance, UTM for the facility and technical support in this project. Authors also would like to acknowledge the Universiti Teknologi MARA (UiTM) for the financial support for my $\mathrm{PhD}$ study.

\section{REFERENCES}

Abdul, W. I. and Halim, S., 2001. Pelarasan Ukur. Dewan Bahasa dan Pustaka, Kuala Lumpur. 385 pages: 5-9.

Brian, F., Catherine, L. C. and Robert, R., 2004. Investigation on Laser Scanners. IWAA2004, CERN, Geneva.

Fraser, C. S., 1996. Network Design. In Close Photogrammetry and Machine Vision (Eds. by K. B. Atkinson). Whittles Publishing, Roseleigh House, Latheronwheel, Scotland, UK. 371 pages: $256-279$.

Gielsdorf, F., Rietdorf, A. and Gruendig, L., 2004. A Concept for the Calibration of Terrestrial Laser Scanners. TS26 Positioning and Measurement Technologies and Practices IILaser Scanning and Photogrammetry. FIG Working Week 2004, Athens, Greece: 1-10.

González-Aguilera, D. Gómez-Lahoz, J. and Sánchez, J., 2008. A new approach for structural monitoring of large dams with a three-dimensional laser scanner. Sensors, 8 (9): 5866-5883.

González-Jorge, H., Riveiro, B., Arias, P. and Armesto, J., 2012. Photogrammetry and laser scanner technology applied to length measurements in car testing laboratories. Measurement 45: 354-363.

Gopal, K. K., 1999. 100 Statistical Test. Thousand Oaks, California: SAGE Publications Ltd. 215 pages: 37-38.

Gordon, S.J. and Lichti, D.D., 2007. Modeling terrestrial laser scanner data for precise structural deformation measurement. ASCE Journal of Surveying Engineering. 133 (2): 72-80.

Lichti, D. D., 2007. Error Modelling, Calibration and Analysis of an AM-CW Terrestrial Laser Scanner System. ISPRS Journal of Photogrammetry \& Remote Sensing 61: 307-324.

Lichti, D. D., 2010a. A Review of Geometric Models and SelfCalibration Methods for Terrestrial Laser Scanner. Bol. Ciênc. Geod., sec. Artigos, Curitiba, 2010:3-19. 
Lichti, D.D., 2010b. Terrestrial Laser Scanner Self Calibration: Correlation Sources and Their Mitigation. ISPRS Journal of Photogrammetry \& Remote Sensing 65: 93-102.

Mohd Azwan, A., Halim, S., Zulkepli, M., Albert K. C., Khairulnizam, M. I. and Anuar, A.. 2013. Calibration and Accuracy Assessment of Leica ScanStation C10 Terrestrial Laser Scanner. Development in Multidimensional Spatial Data Models, Springer Lecture Notes in Geoinformation and Cartography (LNG\&C), March 2013: 33-47.

Mohd Azwan, A., Lichti, D. D., Albert K. C., Halim, S. and Zulkepli, M. 2014. An On-Site Approach for the SelfCalibration of Terrestrial Laser Scanner. Measurement 52: 111123.

Reshetyuk, Y., 2009. Self-Calibration and Direct Georeferencing in Terrestrial Laser Scanning. Doctoral Thesis in Infrastructure, Royal Institute of Technology (KTH), Stockholm, Sweden. 162 pages: 68-69.

Riveiro B., González-Jorge H., Varela M. and Jauregui D.V., 2013. Validation of terrestrial laser scanning and photogrammetry techniques for the measurement of vertical underclearance and beam geometry in structural inspection of bridges. Measurement (46): 184-794.

Rönnholm, P., Nuikka, M., Suominen, A., Salo, P., Hyyppä, H., Pöntinen, P., Haggrén, H., Vermeer, M., Puttonen, J., Hirsi, H., Kukko, A., Kaartinen, H., Hyyppä, J. and Jaakkola, A., 2009. Comparison of measurement techniques and static theory applied to concrete beam deformation. The Photogrammetric Record, 24(128): 351-371.

Syahmi, M. Z., Wan Aziz, W. A., Zulkarnaini, M. A., Anuar, A. and Othman, Z., 2011. The Movement Detection on the Landslide Surface by Using Terrestrial Laser Scanning. Control and System Graduate Research Colloquium (ICSGRC), 2011 IEEE, Shah Alam, Selangor.

Wan Aziz, W. A., Khairul, N. T. and Anuar, A., 2012. Slope Gradient Analysis at Different Resolution Using Terrestrial Laser Scanner. Signal Processing and its Applications (CSPA), 2012 IEEE 8th International Colloquium, Melaka. 